\title{
Sex, stress, and fear: Individual differences in conditioned learning
}

\author{
MICHAEL ZORAWSKI, CRAIG A. COOK, CYNTHIA M. KUHN, and KEVIN S. LABAR \\ Duke University, Durham, North Carolina
}

\begin{abstract}
It has long been recognized that humans vary in their conditionability, yet the factors that contribute to individual variation in emotional learning remain to be delineated. The goal of the present study was to investigate the relationship among sex, stress hormones, and fear conditioning in humans. Forty-five healthy adults ( 22 females) underwent differential delay conditioning, using fear-relevant conditioned stimuli and a shock unconditioned stimulus. Salivary cortisol samples were taken at baseline and after acquisition training and a 24-h-delayed retention test. The results showed that acquisition of conditioning significantly correlated with postacquisition cortisol levels in males, but not in females. This sex-specific relationship was found despite similar overall levels of conditioning, unconditioned responding, and cortisol. There was no effect of postacquisition cortisol on consolidation of fear learning in either sex. These findings have implications for the understanding of individual differences in fear acquisition and risk factors for the development of affective disorders.
\end{abstract}

"In the future, we might with great advantage go back to Pavlov in trying to understand both individual differences and social issues" (Eysenck, 1983, p. 124). Hans Jürgen Eysenck was critical of the field of psychology in the early 1980 s with its strong emphasis on averages, and praised Pavlov (1927) for his appreciation of individual differences. Inspired by this historical perspective, the present article is concerned with individual differences in fear conditioning, an aversive form of classically conditioned learning. This form of emotional learning has been well studied, but the factors that contribute to the individual variation frequently observed with fear-conditioning tasks remain to be delineated.

Fear conditioning plays an important role in the adaptive functioning of organisms across the phyla, since effective learning about dangerous stimuli in the environment is critical for survival. In a typical fear-conditioning procedure, an initially neutral conditioned stimulus (CS) acquires emotional properties through predictive pairings with an aversive unconditioned stimulus (US). Conditioning is established when arousal reactions that constitute the physiologic response to the US come under control of the CS. One component of this response in aversive situations is activation of the hypothalamic-pituitary-adrenal axis, ultimately resulting in increased secretion of glucocorticoids, the adrenocortical stress hormones.

This work was supported in part by National Science Foundation Career Award 0239614 and National Institutes of Health Grant R01 DA14094. We thank Daniel G. Dillon and Bettina Brodtmann for their helpful advice and Judy Johnston for analyzing the cortisol samples. Correspondence concerning this article should be addressed to K. S. LaBar, Center for Cognitive Neuroscience, B203 LSRC Building, Box 90999, Duke University, Durham, NC 27708-0999 (e-mail: klabar@duke.edu).
Glucocorticoids (e.g., cortisol) exhibit individual variations in basal and stress levels (Bartels, de Geus, Kirschbaum, Sluyter, \& Boomsma, 2003; Cools \& Gingras, 1998; Kabbaj, Devine, Savage, \& Akil, 2000; Kirschbaum, Kudielka, Gaab, Schommer, \& Hellhammer, 1999; Meaney et al., 1993; Piazza et al., 1991; Rohleder, Wolf, \& Kirschbaum, 2003; Steptoe et al., 2003; Stone et al., 2001) and play a role in various aspects of learning and memory (Lupien \& McEwen, 1997; McEwen \& Sapolsky, 1995; Roozendaal, 2003; Wolf, 2003). Differences in glucocorticoid reactivity may, therefore, contribute to the individual variation seen in fear conditioning. However, the exact effects that stress and stress hormones have on memory function depend on many factors, such as the time course of the experimental manipulation or endogenous secretion (acute vs. chronic), the mode and stage of memory processing (declarative vs. nondeclarative; acquisition, consolidation, or retrieval), and the emotional characteristics of the eliciting event, as well as dose and sex. Although chronic stress and systemically elevated glucocorticoid levels have been found to impair memory function (Arbel, Kadar, Silbermann, \& Levy, 1994; Bodnoff et al., 1995; Conrad, Galea, Kuroda, \& McEwen, 1996; Luine, Spencer, \& McEwen, 1993; Luine, Villegas, Martinez, \& McEwen, 1994; Newcomer et al., 1999; Park, Campbell, \& Diamond, 2001; Starkman, Gebarski, Berent, \& Schteingart, 1992), the focus of this article is on acute effects.

It has been shown in experimental animals that acute glucocorticoid manipulations facilitate memory consolidation processes (e.g., Flood et al., 1978; Hui et al., 2004; Oitzl \& de Kloet, 1992; Roozendaal \& McGaugh, 1996; Sandi \& Rose, 1994; Zorawski \& Killcross, 2002, 2003; for reviews, see McGaugh, 2004; Roozendaal, 2003 ) but may impair the retrieval of information from 
memory (de Quervain, Roozendaal, \& McGaugh, 1998). These findings have been extended to declarative memory tasks in humans. Exogenous administration of hydrocortisone (Buchanan \& Lovallo, 2001) or postlearning cold pressor stress (Cahill, Gorski, \& Le, 2004) have been shown to enhance memory consolidation selectively for emotional, relative to neutral, material. However, this selectivity has not been supported by other investigators (Abercrombie, Kalin, Thurow, Rosenkranz, \& Davidson, 2003; Maheu, Joober, Beaulieu, \& Lupien, 2004), who have found that hydrocortisone and the corticosteroid synthesis inhibitor metyrapone enhanced and impaired, respectively, long-term memory consolidation for both emotional and neutral material. Impairment of memory retrieval by acute cortisol administration has been found for studied word lists (de Quervain, Roozendaal, Nitsch, McGaugh, \& Hock, 2000), as well as for autobiographical memory (Buss, Wolf, Witt, \& Hellhammer, 2004).

An even more variable picture arises from studies concerned with the acute effects of glucocorticoids on memory acquisition. High endogenous baseline levels or exogenous administration of glucocorticoids or stress prior to the study phase of a memory task is associated with better performance under some circumstances (Abercrombie et al., 2003; Akirav et al., 2004; Beckwith, Petros, Scaglione, \& Nelson, 1986; Bemelmans, Goekoop, De Rijk, \& Van Kempen, 2002; Domes, Heinrichs, Reichwald, \& Hautzinger, 2002; Fehm-Wolfsdorf, Reutter, Zenz, Born, \& Fehm, 1993; Lupien, Wilkinson, Brière, Mènard, et al., 2002; Lupien, Wilkinson, Brière, Ng Ying Kin, et al., 2002; Putman, van Honk, Kessels, Mulder, \& Koppeschaar, 2004; Shors, Weiss, \& Thompson, 1992; Wilson, Wilson, \& Dicara, 1975), but not under others (Kirschbaum, Wolf, May, Wippich, \& Hellhammer, 1996; Lupien et al., 1997; Lupien, Gillin, \& Hauger, 1999; Maheau et al., 2004; Wolf, Convit, et al., 2001; Wolf, Schommer, Hellhammer, McEwen, \& Kirschbaum, 2001; Wolkowitz et al., 1990). Such differences across studies are likely due to complex interactions between such factors as the proposed inverted U-shaped dose response function of glucocorticoids (Conrad, Lupien, \& McEwen, 1999; Diamond, Bennett, Fleshner, \& Rose, 1992; Kovacs, Telegdy, \& Lissak, 1977; Lupien \& McEwen, 1997), putatively distinctive roles of different receptor types (de Kloet, 2004; Lupien \& McEwen, 1997; Oitzl \& de Kloet, 1992; Veldhuis, Van Koppen, Van Ittersum, \& de Kloet, 1982), and the natural diurnal variation in glucocorticoid levels (Fehm-Wolfsdorf et al., 1993; Lupien et al., 1999; Lupien, Wilkinson, Brière, Mènard, et al., 2002). It is also important to consider that it is difficult to dissociate the effects on memory acquisition from the impairing effects on memory retrieval (de Quervain et al., 1998; de Quervain et al., 2000), since some experimental manipulations may affect both phases.

Sex is another important factor that interacts with the way stress and glucocorticoids affect learning and memory. Shors et al. (1992) found that stress facilitates classical conditioning in male rats, both $24 \mathrm{~h}$ later and imme- diately afterward (Shors, 2001). However, the opposite effect was observed in female rats (Shors, 2004; Wood, Beylin, \& Shors, 2001; Wood \& Shors, 1998). Corticosterone levels were correlated with performance in male, but not in female, rats, whose performance depended on the stage of estrus (Wood et al., 2001). The authors suggested that learning in males and females is affected by different hormonal systems and their interaction. A similar sexual dimorphism has been reported in humans, where a relationship between memory performance and cortisol induced by psychosocial stress was observed in males, but not in females (Wolf, Schommer, et al., 2001). Taylor et al. (2000) have gone so far as to propose that females and males exhibit a fundamentally different stress response system both behaviorally and hormonally.

In summary, individual variability in the acquisition and consolidation of learning and memory can be associated with differences in cortisol levels, and this relationship interacts with sex. The role of sex and stress hormones in learning and memory has not yet been systematically investigated with human fear-conditioning paradigms. This is surprising, given that (1) stress and high stress hormone levels have been linked to psychopathology (Erickson, Drevets, \& Schulkin, 2003) and brain atrophy (Sapolsky, 1996), (2) deviant emotional-learning mechanisms have been proposed to play an important role in models of various clinical syndromes, including anxiety disorders (Öhman, 1979; Rosen \& Schulkin, 1998), posttraumatic stress disorder (Brewin, 2001; Layton \& Krikorian, 2002; Orr, Metzger, \& Pitman, 2002), and addiction (Everitt, Dickinson, \& Robbins, 2001; Robinson \& Berridge, 2003), and (3) some of these conditions are associated with sex-specific pathophysiological mechanisms, predispositions, and prevalence rates (e.g., Breslau, 2002; Bryant \& Harvey, 2003; Seedat \& Stein, 2000).

In the present study, healthy adults underwent differential delay conditioning, using fear-relevant CSs and a shock US while skin conductance responses (SCRs) were recorded. To distinguish the contributions of stress hormones to acquisition versus consolidation processes, we conducted a 24-h-delayed extinction test as an assessment of fear retention. Salivary cortisol samples were obtained at baseline and at several points following acquisition training and the extinction test. The conditioning data were interrogated as a function of both cortisol levels and sex. In accord with animal models, we hypothesized that postacquisition cortisol levels would be associated with greater conditioned fear acquisition and retention and that these effects would be larger in male participants. By utilizing this approach, the present study should lead to new insights regarding the contribution of sex and endogenous stress hormones to the individual variability observed during conditioned fear learning.

\section{METHOD}

\section{Participants}

Forty-five healthy participants (22 females), 18-38 years of age (females, $M=23.14$ years, $S D=2.92$; males, $M=26.22$ years, $S D=5.92$ ) were included in the final analysis. The participants 
were screened for a self-reported history of psychiatric and neurological disorders and substance abuse. Due to the fear-relevant nature of the CSs, screening included questionnaires assessing attitudes toward snakes and spiders (Klorman, Hastings, Weerts, Melamed, $\&$ Lang, 1974). Individuals scoring within one $S D$ of the mean of phobics on the snake and spider questionnaires (Fredrikson, 1983) were excluded from participation. Data from 3 additional participants were lost due to technical failure. Eight nonresponders were also excluded, due to excessively low responsiveness to the US. Written informed consent was obtained in accordance with the Institutional Review Board policies at Duke University Medical Center. The participants were recruited by advertising at Duke University and were paid $\$ 25$ for their participation.

\section{Procedure}

To control for the natural diurnal rhythm of cortisol levels, all the sessions took place in the afternoon (when endogenous levels are low), starting at around 2:00 p.m. to 4:00 p.m. (range, 1:47 p.m. to 5:05 p.m.). The participants had been asked to refrain from eating, drinking, smoking, exercising, and chewing gum for $30 \mathrm{~min}$ before coming to the laboratory, since such activities may affect cortisol levels or obscure their measurement.

Day 1. Upon arrival, the participants read and signed the consent form, filled out a personal history questionnaire with demographic and medical background questions, and confirmed that they had not engaged in the activities above before coming to the laboratory. To put the participants in a comparable, relaxed state, they were then shown a neutral 20-min film clip depicting a scenic train ride through British Columbia (Highball Productions, Tucson, AZ). Following the train video, the participants provided a salivary cortisol sample (see the Cortisol Protocol section) and filled out the snake and spider questionnaires. About 45 min after arrival, the participants underwent habituation and acquisition of fear conditioning (see the Fear-Conditioning Protocol section). Immediately following acquisition, the recording electrodes were removed, and the participants washed their hands. About 1 min later, the participants provided a saliva sample for cortisol assessment. The participants then filled out a questionnaire, giving feedback on their subjective experience of the session, using 7-point scales assessing the stressfulness of the study, the irritation caused by the shock, and the emotionality of the snake and spider images. The rest of the session was spent filling out personality questionnaires unrelated to the present study and providing two additional cortisol samples.

Day 2. Upon arrival, at approximately the same time as on Day 1, the participants again confirmed their 30-min abstinence from the aforementioned activities, filled out the Daily Stress Inventory (Brantley, Waggoner, Jones, \& Rappaport, 1987) to assess the degree of stress that they had experienced during the last $24 \mathrm{~h}$, and provided a cortisol sample. They then underwent an extinction test to assess retention of conditioning (see the Fear-Conditioning Protocol section). After washing their hands, the participants were fully debriefed about the purpose of the experiment and were compensated for their participation, prior to providing a final cortisol sample.

\section{Fear-Conditioning Protocol}

Stimulus parameters. On Day 1, the participants underwent habituation and acquisition training consecutively and without a break. On Day 2, they underwent an extinction test. A discrimination procedure was employed in which one visual stimulus $(\mathrm{CS}+$ ) was partially reinforced by a coterminating US during acquisition, whereas another stimulus (CS-) was explicitly unpaired. The habituation phase consisted of 4 trials of each CS type, the acquisition phase consisted of 16 trials of each CS type (5 of the $16 \mathrm{CS}+$ trials were reinforced), and the extinction test consisted of 8 trials of each CS type. During habituation and extinction, none of the CSs was reinforced.

A picture of a snake and a picture of a spider $(22.5 \times 21.5 \mathrm{~cm})$ served as the CSs (duration, $4 \mathrm{sec}$ ). The CSs were presented cen- trally on a 17 -in. computer screen in one of two pseudorandom sequences, subject to the constraint that no more than two trials of the same CS type occurred consecutively (intertrial interval, $14 \pm$ $2 \mathrm{sec}$ ). The choice of sequence and the designation of the snake or the spider as the CS+ were counterbalanced across participants. The snake and spider pictures were taken from the International Affective Picture System (Lang, Bradley, \& Cuthbert, 2001) and were matched in ratings of arousal and valence. Mean luminance of each picture was equated using Photoshop software (Adobe Systems, San Jose, CA).

The US was an electric shock (200-msec duration, delivered at $50 \mathrm{~Hz}$ ) administered transcutaneously over the median nerve of the participants' dominant wrist by a bipolar surface-stimulating electrode (21-mm electrode spacing; Grass-Telefactor Model F-E10S2, West Warwick, RI). The electrode leads were secured by a rubber strap and were attached to a Grass-Telefactor SD-9 stimulator via coaxial cable leads that were shielded and grounded through a radiofrequency filter. A saline-based gel (Sigma Gel; Parker Laboratories, Fairfield, NJ) was used as a conductive electrolyte. Prior to the conditioning session, each participant's tolerance of the US was individually determined, and an appropriate voltage level was selected so that the shocks were regarded as unpleasant and aversive. Voltage was initially set at a low level of $30 \mathrm{~V}$ and was adjusted in $15-\mathrm{V}$ increments until the participants indicated that their tolerance had been reached. The participants were told that only a few stimulation pulses would be delivered and that these would occur at the same intensity. The mean US intensity level $( \pm S D)$ set by the participants included in the final analysis was $66.94 \mathrm{~V}( \pm 21.31)$. SuperLab software (Cedrus, Phoenix, AZ) controlled the stimulus presentation and triggered the shock generator via a National Instruments (Austin, TX) DIO-24 data acquisition card.

Task instructions. Before each session, the participants were informed that they would see pictures of snakes and spiders and might receive occasional shocks. In order to keep the participants attentive to the screen, they were asked to classify the animal category of each CS with their dominant hand, using the number pad of the keyboard (two-alternative forced choice: snake/spider). They were also asked to keep their nondominant hand still to avoid movement artifacts in the SCR recording electrodes.

Skin conductance measurements. SCRs were used as the dependent measure of conditioning, as described previously (LaBar, Cook, Torpey, \& Welsh-Bohmer, 2004; LaBar, Gatenby, Gore, LeDoux, \& Phelps, 1998). SCRs were monitored from the participants' nondominant hand, using $\mathrm{Ag}-\mathrm{AgCl}$ electrodes attached to the middle phalanges of the second and third digits by Velcro straps (BIOPAC Systems, Goleta, CA). A saline-based gel (Sigma Gel) was used as a conductive electrolyte. Skin conductance was monitored at $250 \mathrm{~Hz}$ and was stored off line for analysis, using AcqKnowledge software (BIOPAC Systems, Goleta, CA). Physiologic recording was synchronized to the stimulus presentation by a National Instruments DIO-24 card. The physiologic data were scored according to conventional methods, as previously described (LaBar et al., 2004; LaBar et al., 1998). For inclusion in the data analysis, the following criteria were established: SCR latency $=1-4 \mathrm{sec}$, SCR duration $=0.5-5 \mathrm{sec}$, and minimum SCR amplitude $=0.02$ microsiemens $(\mu \mathrm{S})$. Responses that did not meet these criteria were scored as zero.

Data analysis. Prior to statistical analysis, conditioned SCRs were collapsed into early and late trial blocks of the habituation and acquisition phases. Each of these blocks consisted of a mean of two trials per CS type for the habituation phase and a mean of 8 trials per CS type for the acquisition phase. The 24-h-delayed extinction test was not subdivided into blocks, so the data reflect a mean of eight trials per CS type. Learning-related changes were hypothesized to be found in the late acquisition phase, as had been reported previously (LaBar et al., 2004; LaBar, LeDoux, Spencer, \& Phelps, 1995), whereas retention performance in the 24-h-delayed extinction test was thought to reflect consolidation of learning. Prior to 
statistical analysis, conditioned SCRs were square-root transformed to reduce skewness and were range corrected (LaBar et al., 2004).

Differential SCR scores were also calculated as an index of learning by subtracting responses to the $\mathrm{CS}-$ from those to the $\mathrm{CS}+$ across trial blocks. According to this measure, difference scores of zero reflect no differential learning, whereas difference scores above zero do (LaBar et al., 2004; LaBar et al., 1995). These difference scores were used to investigate the relationship with cortisol levels, using median split and Pearson correlation coefficient methods. All other effects were analyzed using mixed analyses of variance (ANOVAs), with post hoc ANOVAs and Bonferronicorrected $t$ tests to evaluate simple effects, as appropriate. An alpha level of .05 was set for all the analyses.

\section{Cortisol Protocol}

Saliva collection. Given the temporal dynamics of cortisol's entry into saliva by passive diffusion and the fact that saliva cortisol levels typically peak about $30 \mathrm{~min}$ after a stressor (Kirschbaum $\&$ Hellhammer, 1994), the following sample time points were chosen: for Day 1, approximately $15 \mathrm{~min}$ before (baseline) and 15, 30, and $45 \mathrm{~min}$ after the beginning of the conditioning procedure; for Day 2, approximately $5 \mathrm{~min}$ before and $30 \mathrm{~min}$ after the beginning of the extinction procedure. In order to assess diurnal changes in cortisol and, thereby, confirm the sensitivity of the measurements, the participants were asked to provide one additional sample in the evening of Day 1, provided that they had refrained from eating, drinking, smoking, exercising, and chewing gum for $30 \mathrm{~min}$ before, and one sample in the morning of Day 2, immediately after waking up. These samples were collected by the participants themselves at home. For saliva collection, the participants placed a cotton dental swab, a Salivette (Sarstedt, Newton, NC), in their mouth for about $30 \mathrm{sec}$. Samples were labeled and refrigerated until assayed. Numerous studies have shown that saliva cortisol levels approximate free, non-protein-bound cortisol and that the method of collection (stimulated or unstimulated) influences only the volume collected, not the cortisol concentration (Kirschbaum \& Hellhammer, 1994; Riad-Fahmy, Read, Walker, \& Griffiths, 1982). Unlike measurement of other hormones (e.g., testosterone), the cotton swabbing method has been shown to be reliable and accurate for cortisol measurement (Shirtcliff, Granger, Schwartz, \& Curran, 2001).

Assay. Cortisol was measured by ELISA, using a kit from Oxford Biomedical Research (Oxford, MI), directly in saliva after freeze thawing and centrifugation. The sensitivity of the assay is $0.05 \mathrm{ng} / \mathrm{ml}$. Standards and low and high controls are run in every assay. The inter- and intra-assay coefficients of variation on the assay are less than $10 \%$ and $5 \%$, respectively.

\section{RESULTS}

\section{Fear Conditioning}

Males and females did not differ in their mean unconditioned SCRs to the shock (females, $M=0.81 \mu \mathrm{S}, S D=$ 0.09 ; males, $M=0.78 \mu \mathrm{S}, S D=0.11 ; t<1)$ or in their self-selected voltage level of the shock (females, $M=$ $63.86 \mathrm{~V}, S D=22.02$; males, $M=69.89 \mathrm{~V}, S D=20.65$; $t<1$ ). These data indicate similar US responsivity as a function of sex.

Conditioning data from Day 1 were analyzed with a four-way mixed ANOVA, with sex (female or male) as a between-groups factor and $\mathrm{CS}$ type (CS+ or $\mathrm{CS}-$ ), phase (habituation or acquisition), and block (early or late) as repeated measures (Figure 1). The results showed a significant three-way CS type $\times$ phase $\times$ block interaction $[F(1,43)=11.03, p<.01]$. As was predicted, a simple effects analysis revealed that responses to the $\mathrm{CS}+$ were greater than those to the $\mathrm{CS}-$ in late acquisition $[F(1,44)=$ $35.76, p<.001]$. Responses to the CS + and the CS - did not differ in the early or late phase of habituation (both $F \mathrm{~s}<1)$ or in the early phase of acquisition $[F(1,44)=$ $2.17, p=.15]$. There was no main effect of sex and no interaction of sex with CS type or phase (all $F \mathrm{~s}<1$ ).

To establish whether conditioned responding was retained after $24 \mathrm{~h}$ and remained above baseline levels, a planned contrast was conducted across conditioned responses in the extinction test, the late acquisition phase, and the late habituation phase. A three-way sex (female or male) $\times$ CS type $(\mathrm{CS}+$ or $\mathrm{CS}-) \times$ phase (late habituation, late acquisition, or extinction test) ANOVA yielded a significant interaction between CS type and phase $[F(1,44)=10.88, p<.001]$. Simple effects analyses confirmed successful retention of conditioning by showing greater responses to the $\mathrm{CS}+$ than to the $\mathrm{CS}-$ in the extinction test $[F(1,44)=16.90, p<.001]$. These analyses also revealed that $\mathrm{CS}+$ responding differed across phases $[F(2,88)=4.84, p<.01]$, with greater responses elicited to the $\mathrm{CS}+$ in the extinction test than in late habituation $[t(1,44)=-2.04, p<.05]$ and no difference in responding to the $\mathrm{CS}+$ between the extinction test and late acquisition $[t(1,44)=1.11, p=.27]$. Responses to the CS - did not differ across the extinction test, late acquisition, and late habituation $[F(2,88)=$ $1.16, p=.32]$. There were no main effects of or interactions with sex (all $\left.F_{\mathrm{s}}<1\right)$.

\section{Cortisol Levels}

Cortisol samples were analyzed with a two-way mixed ANOVA with sex (female or male) as a between-groups factor and cortisol sample (samples 1-8) as a repeated measure (Figure 2). There was a significant main effect of cortisol sample $[F(7,294)=23.50, p<.001]$. Bonferronicorrected paired $t$ tests revealed that the morning sample on Day 2 was higher than all the other samples ( $p$ s $<$ .001 ), constituting the typical morning cortisol peak, and confirming that the cortisol assessment was sensitive to diurnal variations. It was also found that Sample 1 on Day 1 (15 min before the beginning of conditioning) was significantly higher than Samples 3, 4, and 5 (taken 30 and $45 \mathrm{~min}$ after the beginning of conditioning and in the evening, respectively; $p \mathrm{~s} \leq .05$ ). This reduction in cortisol levels was likely due to the participants' settling in at the lab and/or experiencing a natural diurnal decrease across the afternoon. It is important to note that conditioning did not lead to a cortisol elevation in the group average. There was no main effect of $\operatorname{sex}(F<1)$ and no interaction between sex and cortisol sample $[F(7,294)=$ $1.25, p=.28]$.

\section{Conditioning, Cortisol, and Sex}

Behaviorally, conditioning was best observed in the late phase of acquisition, as was predicted. Given the temporal dynamics of saliva cortisol assessment (see the Cortisol Protocol section), the most appropriate time point at which to link endogenous cortisol to late acquisition was Sample 4, obtained about 45 min after the beginning of 

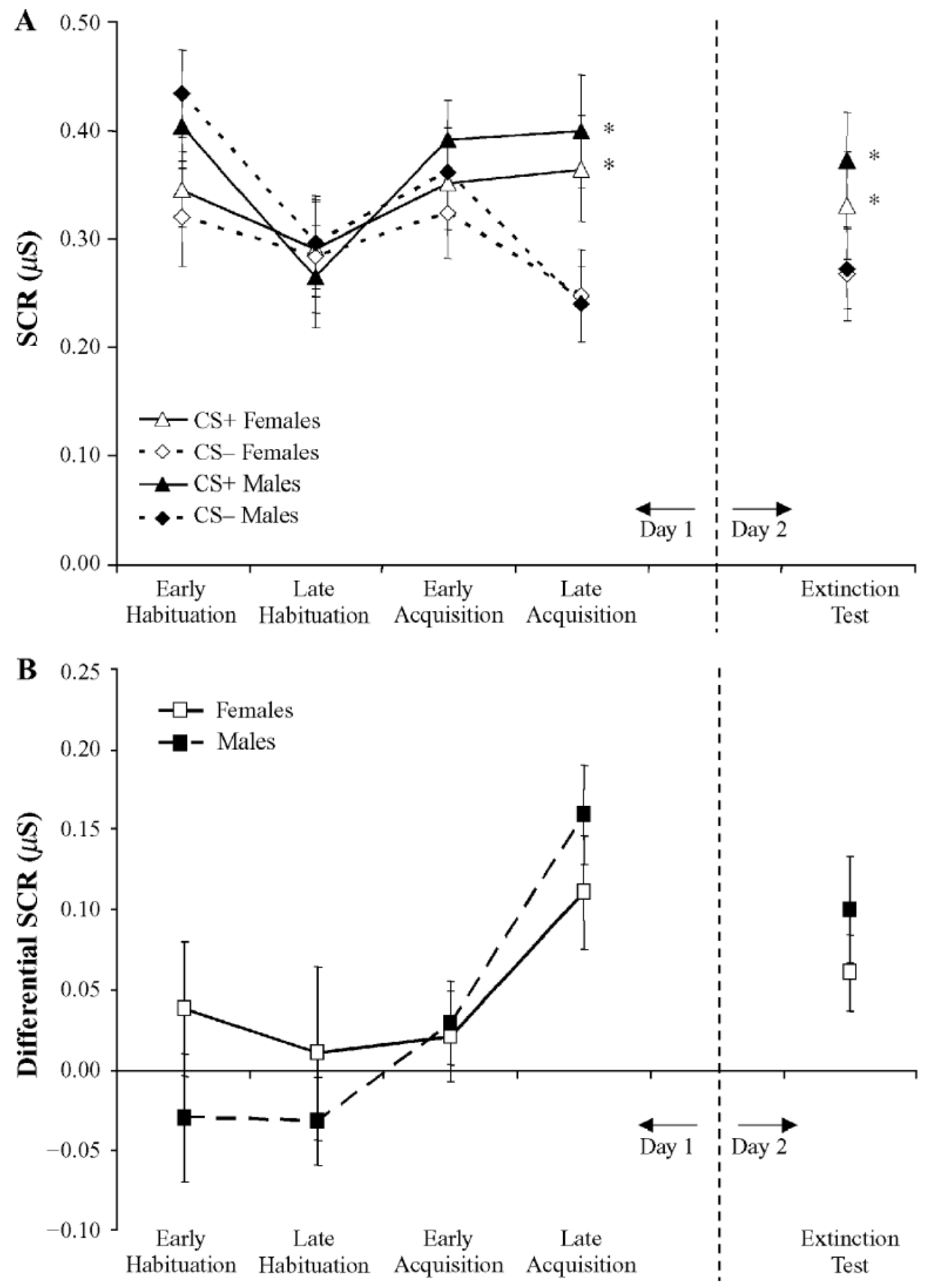

Figure 1. (A) Mean skin conductance responses (SCRs) to the reinforced conditioned stimulus $(\mathrm{CS}+)$ and the nonreinforced conditioned stimulus $(\mathrm{CS}-)$ in females and males across different phases of conditioning and the 24-h-delayed extinction test. $\quad * p<.001(\mathrm{CS}+$ vs. CS-). (B) Differential SCR expressed as the difference between $\mathrm{CS}+$ and $\mathrm{CS}-. \mu \mathrm{S}=$ microsiemens. Error bars represent standard errors of the means.

conditioning (and about 30-35 min after late acquisition). To investigate the relationship among cortisol levels, sex, and acquisition/consolidation of conditioned learning, two sets of analyses were conducted.

In the first analysis, female and male participants were divided by median split into high- and low-cortisol groups, according to postacquisition levels (Sample 4). A three- way mixed ANOVA, with sex (female or male) and cortisol group (high or low) as between-groups factors and phase (late acquisition or extinction test) as a repeated measure, was carried out (see Figure 3). The results showed a significant three-way interaction $[F(1,40)=$ $9.80, p<.01]$. Follow-up ANOVAs were conducted by sex. In males, there was a significant interaction between 


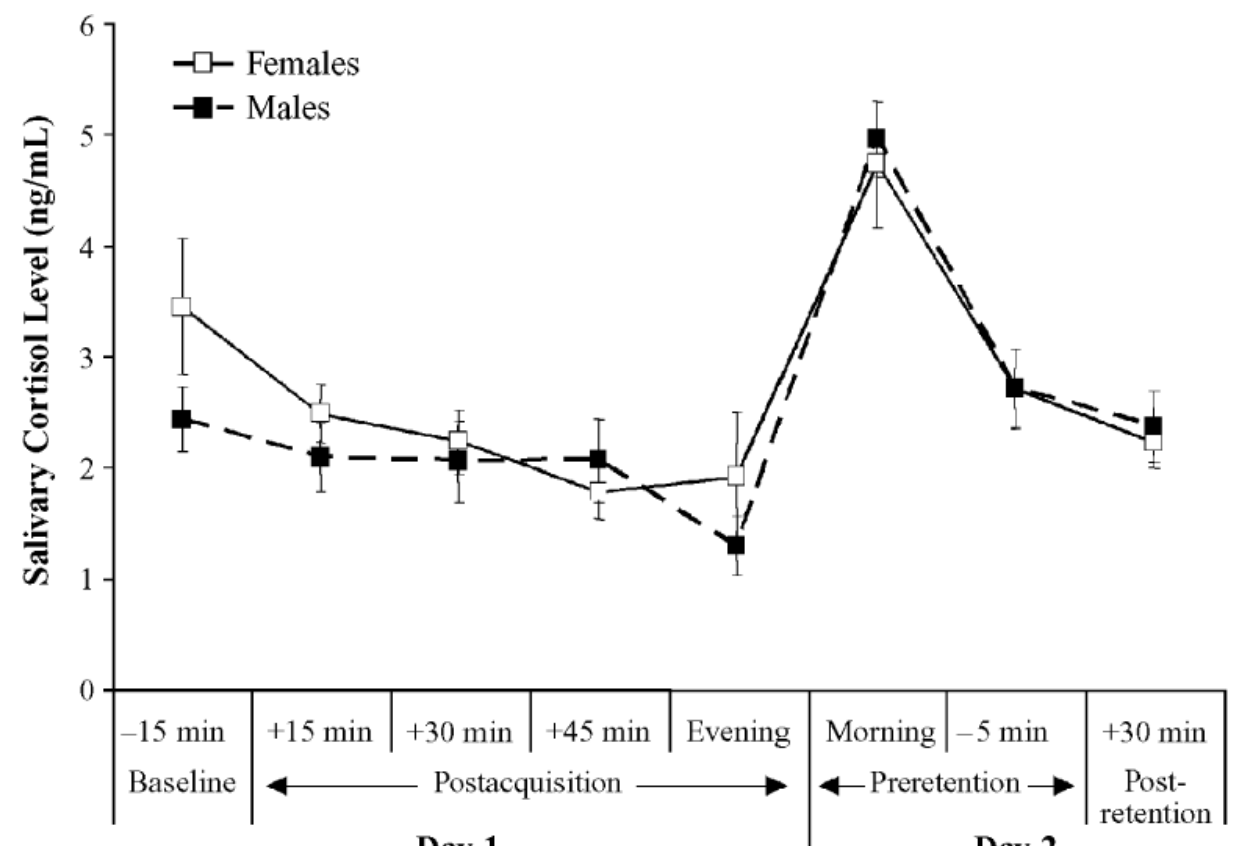

Day 1

Day 2

Sample Time Point

Figure 2. Salivary cortisol levels of females and males at various time points of the experiment. Time points are expressed relative to the beginning of the conditioning session (on Day 1) and the beginning of the extinction test session (on Day 2). Error bars represent standard errors of the means.

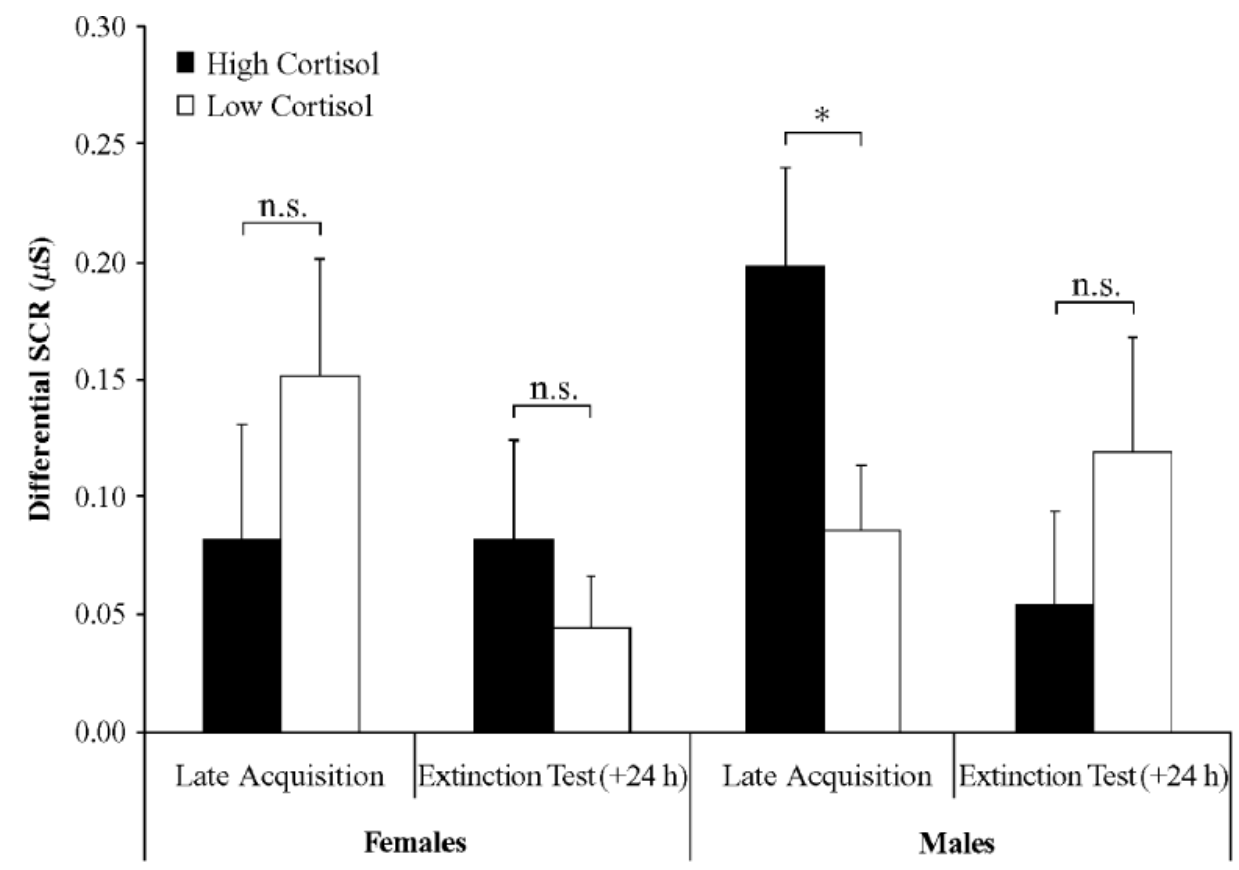

Figure 3. Differential skin conductance responses (SCRs), expressed as the difference between $\mathrm{CS}+$ and $\mathrm{CS}-$, during late acquisition and the 24-h-delayed extinction test in females and males as a function of cortisol level. The participants were assigned to high- and low-cortisol groups according to a median split of postacquisition salivary cortisol levels $(+45 \mathrm{~min}) . \quad{ }^{*} p<.04 ; \mathrm{n} . \mathrm{s} . \quad$ not significant. Error bars represent standard errors of the means. 
cortisol group and phase $[F(1,20)=6.94, p<.02]$. Simple effects analyses revealed that the high-cortisol group showed greater conditioned responding in late acquisition than the low-cortisol group did $[F(1,20)=5.10, p<$ .04]. This difference was not present during the retention test $24 \mathrm{~h}$ later $[F(1,20)=1.19, p=.29]$. In females, the interaction between cortisol group and phase was not significant, and simple effects analyses confirmed that there were no significant differences as a function of cortisol group either during late acquisition $[F(1,20)=$ $1.05, p=.32]$ or during the extinction test $(F<1)$.

In the second analysis, Pearson correlation coefficients were calculated between postacquisition cortisol levels (Sample 4) and differential SCRs obtained during late acquisition (see Figure 4) and retention. Inspection of the data revealed one statistical outlier, who was removed from the analysis. In line with the median-split analysis, there was a significant correlation between postacquisition cortisol levels and late acquisition of conditioning in males $[r(21)=.49, p<.02]$, but not in females $[r(21)=$ $-.03, p=.89]$. Postacquisition cortisol levels and retention of conditioning was not correlated either in females $[r(19)=.01, p=.97]$ or in males $[r(21)=.01, p=.99]$.

Thus, as was predicted, converging data across the two analysis methods revealed a meaningful relationship between postacquisition cortisol levels and conditioned fear acquisition in male, but not in female, participants. This pattern did not generalize to baseline cortisol levels. In contrast to our hypotheses, however, there was no relationship between postacquisition cortisol levels and retention of conditioned fear in either sex.

\section{Subjective Measures}

Females rated the study as a whole as more stressful [females, $M=3.59, S D=1.40$; males, $M=2.70, S D=$ $1.43 ; t(21)=2.12, p<.04]$ and the shock as more irritating [females, $M=4.50, S D=1.44$; males, $M=3.48$, $S D=1.27 ; t(21)=2.52, p<.02]$ than their male coun- terparts did. There were no significant sex differences in perceived emotionality of the snake and spider CSs or in the degree of personal stress experienced between the testing sessions, as measured by the Daily Stress Inventory $(t \mathrm{~s}<1)$.

\section{DISCUSSION}

Eysenck (1983) was keenly aware of the potential utility of Pavlov's approaches to elucidating the mechanisms underlying individual variation in emotional learning and social behavior. In this spirit, in the present study, we investigated the role of sex and stress hormones in the acquisition and retention of conditioning to fearrelevant stimuli in healthy adults. We found a positive relationship between acquisition of fear conditioning and postacquisition salivary cortisol levels in male, but not in female, participants. This result occurred despite the females' reporting greater subjective stress and irritation during the procedure. The sex-mediated cortisol effect was specific to fear acquisition and did not predict retention in a 24-h-delayed extinction test. Importantly, there were no overall differences in conditioned responding, unconditioned responding, or cortisol level as a function of sex. These findings illustrate the value of idiothetic data-analytic strategies in revealing sexually dimorphic influences on emotional learning.

The correlation between postacquisition cortisol level and acquisition of conditioning in males is consistent with a number of studies linking glucocorticoids to facilitated acquisition of learning and memory (Abercrombie et al., 2003; Akirav et al., 2004; Beckwith et al., 1986; Domes et al., 2002; Lupien, Wilkinson, Brière, Mènard, et al., 2002; Lupien, Wilkinson, Brière, Ng Ying Kin, et al., 2002; Shors, 2001; Shors et al., 1992). Most of these studies involved such experimental manipulations as the prelearning administration of stress, glucocorticoids, or the glucocorticoid synthesis inhibitor metyrapone. In
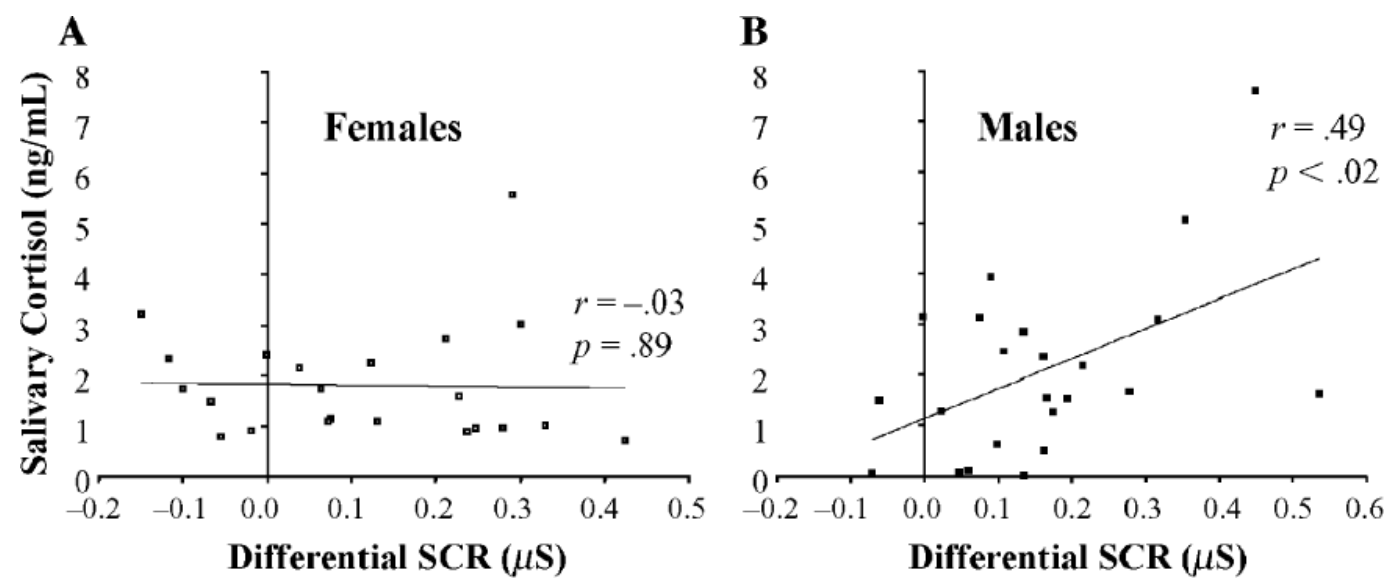

Figure 4. Correlation between differential skin conductance responses (SCRs), expressed as the difference between $\mathrm{CS}+$ and $\mathrm{CS}-$, during late acquisition of conditioning and postacquisition salivary cortisol levels $(+45 \mathrm{~min})$ in female (A) and male (B) participants. 
contrast, in the present study, endogenous cortisol levels were examined as they occur naturally in the context of the experimental procedure. Thus, our approach has greater ecological validity, albeit with less specificity regarding the causal directionality of the effect (given that the result is correlational by nature). Despite these methodological differences, all of these studies have revealed acute beneficial effects of stress hormones, which complements other results linking higher basal cortisol levels to improved declarative memory function (Bemelmans et al., 2004; Putman et al., 2004).

There are, however, a number of other reports demonstrating impaired memory acquisition following acute stress level manipulation by either psychosocial stress (Kirschbaum et al., 1996; Lupien et al., 1997; Wolf, Schommer, et al., 2001) or glucocorticoid administration (Lupien et al., 1999; Wolf, Convit, et al., 2001; Wolkowitz et al., 1990). A number of reasons could explain these contradictory findings. First, in typical declarative memory paradigms, it is difficult to dissociate the effects of pretraining hormone manipulations on the acquisition phase from those on the retrieval phase. This is especially problematic if the two experimental phases are close in time and cortisol levels remain elevated during retrieval, since retrieval processes have been shown to be negatively affected by glucocorticoids (Buss et al., 2004; de Quervain et al., 1998; de Quervain et al., 2000; Roozendaal, 2003).

Second, it has been proposed that the effects of glucocorticoids on cognition follow an inverted U-shaped function (Diamond et al., 1992; Kovacs et al., 1977; Lupien \& McEwen, 1997) and that two classes of steroid receptors subserve different cognitive processes (Lupien \& McEwen, 1997; Oitzl, van Haarst, \& de Kloet, 1997). The low-threshold high-affinity mineralocorticoid receptors (MRs) are largely occupied by endogenous glucocorticoids under basal conditions, whereas the highthreshold low-affinity glucocorticoid receptors (GRs) are primarily activated in situations of stress or during the circadian peak (de Kloet, Oitzl, \& Joels, 1993; Reul $\&$ de Kloet, 1985; Reul et al., 2000). MRs have been suggested to play a role in nonspecific aspects of memory acquisition and encoding, such as sensory integration, selective attention, cognitive efficiency, and adaptive behavioral responses in novel situations (Lupien \& McEwen, 1997; Lupien, Wilkinson, Brière, Mènard, et al., 2002; Oitzl \& de Kloet, 1992; Oitzl et al., 1997; Sandi \& Rose, 1994), whereas GRs are thought to play an important role in the consolidation of emotional memories (Oitzl \& de Kloet, 1992; Roozendaal, 2003; Sandi \& Rose, 1994; Zorawski \& Killcross, 2002). Different experimental conditions, employing different magnitudes of stress or hormone level manipulation at different time points along the natural diurnal cycle of endogenous glucocorticoid secretion, may result in different MR and GR occupation ratios, thus leading to different cognitive effects.

The present study showed a relationship between endogenous postacquisition cortisol levels and acquisition of conditioning. Since the experiment took place in the afternoon, during the circadian trough, and since the experimental procedure itself did not lead to an elevation of cortisol levels, it is possible that the observed relationship was mediated mainly by MRs (Wood et al., 2001), with greater MR occupancy leading to increased levels of sensory integration or selective attention and, hence, better acquisition of conditioning. This hypothesis is also in line with the absence of a relationship between cortisol levels and memory consolidation, measured in the 24-h-delayed retention test. Memory consolidation is thought to be enhanced by GR activation (Roozendaal, 2003). Thus, the modulatory effects of glucocorticoids on memory consolidation observed in previous animal and human studies (e.g., Abercrombie et al., 2003; Buchanan \& Lovallo, 2001; Flood et al., 1978; Hui et al., 2004; Oitzl \& de Kloet, 1992; Roozendaal \& McGaugh, 1996; Sandi \& Rose, 1994; Zorawski \& Killcross, 2002) may apply only to a much higher range of stress levels or exogenously achieved glucocorticoid levels, accompanied by greater levels of GR occupancy, than that in the present experiment.

The exact mechanisms by which glucocorticoids acutely influence different aspects of memory are not yet fully understood. However, their rapid effects, observed in many studies, suggest that nongenomic actions must be involved (de Kloet, 2004; Lupien, Wilkinson, Brière, Mènard, et al., 2002; Schumacher, 1990). Roozendaal (2003) has suggested that the adrenocortical system may interact with the noradrenergic system in this regard (see also Ferry \& McGaugh, 2000; Maheu et al., 2004; McGaugh, McIntyre, \& Power, 2002; Quirarte, Roozendaal, \& McGaugh, 1997). Although this model has been proposed to explain glucocorticoid effects on memory consolidation, it is possible that rapid facilitation of noradrenergic transmission also aids the acquisition of conditioning. For example, Strange, Hurlemann, and Dolan (2003) found that the $\beta$-adrenergic antagonist propranolol, which traditionally has been linked with abolishing the facilitatory effect of emotion on long-term memory consolidation (Cahill, Prins, Weber, \& McGaugh, 1994), also has immediate effects on emotional memory (see Cahill, 2003, for a commentary), thus implicating a role of the noradrenergic system in memory acquisition, possibly by enhancing attentional processes in the amygdala (Gallagher \& Holland, 1994; Selden, Robbins, \& Everitt, 1990).

Animal models of conditioning support the idea that the effects of stress and stress hormones interact with sex. Stress-enhanced fear conditioning occurs only in male rats (Shors, 2001, 2004; Wood \& Shors, 1998), whereas female rats exhibit a stress-related impairment that is abolished by ovarectomy or administration of an estrogen antagonist (Wood \& Shors, 1998). In accord with the present study, Wood et al. (2001) found that conditioning performance correlated with corticosterone levels in males, but not in females, an effect attributed to MRs, rather than to GRs. These results led the researchers to suggest that estrogens might modulate the effects of stress on cognition (see also Wolf, Schommer, et al., 2001), possibly by affecting MR affinity and availability. 
They emphasized that although the sex-specific pattern of results could be either adaptive or epiphenomenal, it underlines the complexity of the relationship between sex, stress, and learning (Shors, 2004). Taylor et al. (2000) have gone even further in proposing that females have a different biobehavioral response system to stress mediated by oxytocin, estrogen, and endogenous opioid peptides, modulating the usual fight-or-flight response by a behavioral pattern of tend and befriend. Given that estrogen levels vary across the menstrual cycle, it is possible that our sex difference might have been reduced if we had tested only women whose estrogen levels were low at the time of testing. Although we acquired information regarding birth control use and the date of our female participants' last period, inclusion of these factors in the statistical analyses did not yield any significant effects. Future studies with larger sample sizes are needed to investigate this issue further, along with consideration of the levels of other gonadal steroids, such as progesterone and testosterone.

\section{CONCLUSION}

Individual differences in brain-behavior relationships relevant for understanding emotional and mnemonic functions represent an emerging and important area of study (Hamann \& Canli, 2004). For instance, recent work suggests that such variables as sex (Cahill et al., 2001; Hamann, Herman, Nolan, \& Wallen, 2004), personality (Canli et al., 2001), racial bias (Phelps et al., 2000), and genotype (Furmark et al., 2004) contribute to individual variation in amygdala activity. Fear conditioning has been proposed as a behavioral systems model of amygdala functioning and its dysregulation in affective illness (Carey, 1990; Öhman, 1979). The results of the present study reveal a sex-specific relationship between acute cortisol levels and conditioned fear acquisition in humans. Our approach highlights the utility of investigating individual differences in emotional learning, with implications for understanding the complex interactions among sex, stress, fear, and their neurohormonal bases. Future applications of this work may contribute to better prevention and treatment of the psychopathological conditions associated with stress and emotion, especially with respect to the mediating influence of sex.

\section{REFERENCES}

Abercrombie, H. C., Kalin, N. H., Thurow, M. E., Rosenkranz, M. A., \& Davidson, R. J. (2003). Cortisol variation in humans affects memory for emotionally laden and neutral information. Behavioral Neuroscience, 117, 505-516.

Akirav, I., Kozenicky, M., Tal, D., Sandi, C., Venero, C., \& RichterLEvin, G. (2004). A facilitative role for corticosterone in the acquisition of a spatial task under moderate stress. Learning \& Memory, 11, 188-195.

Arbel, I., Kadar, T., Silbermann, M., \& Levy, A. (1994). The effects of long-term corticosterone administration on hippocampal morphology and cognitive performance of middle-aged rats. Brain Research, 657, 227-235.

Bartels, M., de Geus, E. J. C., Kirschbaum, C., Sluyter, F., \& Boomsma, D. I. (2003). Heritability of daytime cortisol levels in children. Behavior Genetics, 33, 421-433.
Beckwith, B. E., Petros, T. V., Scaglione, C., \& Nelson, J. (1986). Dose-dependent effects of hydrocortisone on memory in human males. Physiology \& Behavior, 36, 283-286.

Bemelmans, K. J., Goekoop, J. G., De Rijk, R., \& Van Kempen, G. M. J. (2003). Recall performance, plasma cortisol and plasma norepinephrine in normal human subjects. Biological Psychology, 62, 1-15.

Bodnoff, S. R., Humphreys, A. G., Lehman, J. C., Diamond, D. M., Rose, G. M., \& Meaney, M. J. (1995). Enduring effects of chronic corticosterone treatment on spatial learning, synaptic plasticity, and hippocampal neuropathology in young and mid-aged rats. Journal of Neuroscience, 15, 61-69.

Brantley, P. J., Waggoner, C. D., Jones, G. N., \& Rappaport, N. B. (1987). A daily stress inventory: Development, reliability, and validity. Journal of Behavioral Medicine, 10, 61-74.

Breslau, N. (2002). Gender differences in trauma and posttraumatic stress disorder. Journal of Gender-Specific Medicine, 5, 34-40.

BrewIN, C. R. (2001). A cognitive neuroscience account of posttraumatic stress disorder and its treatment. Behaviour Research \& Therapy, 39, 373-393.

Bryant, R. A., \& Harvey, A. G. (2003). Gender differences in the relationship between acute stress disorder and posttraumatic stress disorder following motor vehicle accidents. Australian \& New Zealand Journal of Psychiatry, 37, 226-229.

Buchanan, T. W., \& Lovallo, W. R. (2001). Enhanced memory for emotional material following stress-level cortisol treatment in humans. Psychoneuroendocrinology, 26, 307-317.

Buss, C., Wolf, O. T., Witt, J., \& Hellhammer, D. H. (2004). Autobiographic memory impairment following acute cortisol administration. Psychoneuroendocrinology, 29, 1093-1096.

CAHILL, L. (2003). Similar neural mechanisms for emotion-induced memory impairment and enhancement. Proceedings of the National Academy of Sciences, 100, 13123-13124.

CAHILL, L., GoRSKI, L., \& LE, K. (2004). Enhanced human memory consolidation with post-learning stress: Interaction with the degree of arousal at encoding. Learning \& Memory, 10, 270-274.

Cahill, L., Haier, R. J., White, N. S., Fallon, J., Kilpatrick, L., LaWrence, C., Potkin, S. G., \& Alkire, M. T. (2001). Sex-related difference in amygdala activity during emotionally influenced memory storage. Neurobiology of Learning \& Memory, 75, 1-9.

Cahill, L., Prins, B., Weber, M., \& McGaugh, J. L. (1994). Betaadrenergic activation and memory for emotional events. Nature, 371, 702-704.

Canli, T., Zhao, Z., Desmond, J. E., Kang, E., Gross, J., \& Gabrieli, J. D. E. (2001). An fMRI study of personality influences on brain reactivity to emotional stimuli. Behavioral Neuroscience, 115, 33-42.

CAREY, G. (1990). Genes, fears, phobias, and phobic disorders. Journal of Counseling \& Development, 68, 628-632.

Conrad, C. D., Galea, L. A., Kuroda, Y., \& McEwen, B. S. (1996). Chronic stress impairs rat spatial memory on the Y maze, and this effect is blocked by tianeptine pretreatment. Behavioral Neuroscience, 110, 1321-1334.

Conrad, C. D., Lupien, S. J., \& McEwen, B. S. (1999). Support for a bimodal role for Type II adrenal steroid receptors in spatial memory. Neurobiology of Learning \& Memory, 72, 39-46.

Cools, A. R., \& Gingras, M. A. (1998). Nijmegen high and low responders to novelty: A new tool in the search after the neurobiology of drug abuse liability. Pharmacology Biochemistry \& Behavior, 60, 151-159.

DE KLOET, E. R. (2004). Hormones and the stressed brain. In K. Pacak, G. Aguilera, E. Sabban, \& R. Kvetnansky (Eds.), Stress: Current neuroendocrine and genetic approaches (Annals of the New York Academy of Sciences, Vol. 1018, pp. 1-15). New York: New York Academy of Sciences.

De Kloet, E. R., Oitzl, M. S., \& Joels, M. (1993). Functional implications of brain corticosteroid receptor diversity. Cellular \& Molecular Neurobiology, 13, 433-455.

de Quervain, D. J.-F., Roozendaal, B., \& McGaugh, J. L. (1998). Stress and glucocorticoids impair retrieval of long-term spatial memory. Nature, 394, 787-790.

De Quervain, D. J.-F., Roozendaal, B., Nitsch, R. M., McGaugh, J. L., \& Hock, C. (2000). Acute cortisone administration impairs re- 
trieval of long-term declarative memory in humans. Nature Neuroscience, 3, 313-314.

Diamond, D. M., Bennett, M. C., Fleshner, M., \& Rose, G. (1992). Inverted-U relationship between the level of peripheral corticosterone and the magnitude of hippocampal primed burst potentiation. Hippocampus, 2, 421-430.

Domes, G., Heinrichs, M., Reichwald, U., \& Hautzinger, M. (2002). Hypothalamic-pituitary-adrenal axis reactivity to psychological stress and memory in middle-aged women: High responders exhibit enhanced declarative memory performance. Psychoneuroendocrinology, 27, 843-853.

Erickson, K., Drevets, W., \& Schulkin, J. (2003). Glucocorticoid regulation of diverse cognitive functions in normal and pathological emotional states. Neuroscience \& Biobehavioral Reviews, 27, 233246.

Everitt, B. J., Dickinson, A., \& RobBins, T. W. (2001). The neuropsychological basis of addictive behaviour. Brain Research Reviews, 36, 129-138.

EysENCK, H. J. (1983). The social application of Pavlovian theories. Pavlovian Journal of Biological Science, 18, 117-125.

Fehm-Wolfsdorf, G., Reutter, K., Zenz, H., Born, J., \& Fehm, H. L. (1993). Are circadian variations in taste thresholds cortisol-dependent? Journal of Psychophysiology, 7, 65-72.

Ferry, B., \& McGaugh, J. L. (2000). Role of amygdala norepinephrine in mediating stress hormone regulation of memory storage. Acta Pharmacologica Sinica, 21, 481-493.

Flood, J. F., Vidal, D., Bennett, E. L., Orme, A. E., Vasquez, S., \& JARVIK, M. E. (1978). Memory facilitating and anti-amnesic effects of corticosteroids. Pharmacology Biochemistry \& Behavior, 8, 8187.

FREDRIKSON, M. (1983). Reliability and validity of some specific fear questionnaires. Scandinavian Journal of Psychology, 24, 331-334.

Furmark, T., Tillfors, M., Garpenstrand, H., Marteinsdottir, I., LÅngSTRÖM, B., Oreland, L., \& Fredrikson, M. (2004). Serotonin transporter polymorphism related to amygdala excitability and symptom severity in patients with social phobia. Neuroscience Letters, 362, 189-192.

Gallagher, M., \& Holland, P. C. (1994). The amygdala complex: Multiple roles in associative learning and attention. Proceedings of the National Academy of Sciences, 91, 11771-11776.

HAMANN, S., \& CANLI, T. (2004). Individual differences in emotion processing. Current Opinion in Neurobiology, 14, 233-238.

Hamann, S., Herman, R. A., Nolan, C. L., \& Wallen, K. (2004). Men and women differ in amygdala response to visual sexual stimuli. $\mathrm{Na}$ ture Neuroscience, 7, 411-416.

Hui, G. K., Figueroa, I. R., Poytress B. S., Roozendaal, B., McGaugh, J. L., \& Weinberger, N. (2004). Memory enhancement of classical fear conditioning by post-training injections of corticosterone in rats. Neurobiology of Learning \& Memory, 81, 67-74.

Kabbaj, M., Devine, D. P., Savage, V. R., \& Akil, H. (2000). Neurobiological correlates of individual differences in novelty-seeking behavior in the rat: Differential expression of stress-related molecules. Journal of Neuroscience, 20, 6983-6988.

Kirschbaum, C., \& Hellhammer, D. H. (1994). Salivary cortisol in psychoneuroendocrine research: Recent developments and applications. Psychoneuroendocrinology, 19, 313-333.

Kirschbaum, C., KudielKa, B. M., GaAb, J., Schommer, N. C., \& Hellhammer, D. H. (1999). Impact of gender, menstrual cycle phase, and oral contraceptives on the activity of the hypothalamus-pituitaryadrenal axis. Psychosomatic Medicine, 61, 154-162.

Kirschbaum, C., Wolf, O. T., May, M., Wippich, W., \& Hellhammer, D. H. (1996). Stress- and treatment-induced elevations of cortisol levels associated with impaired declarative memory in humans. Life Sciences, 58, 1475-1483.

Klorman, R., Hastings, J. E., Weerts, T. C., Melamed, B. G., \& LANG, P. J. (1974). Psychometric description of some specific-fear questionnaires. Behavior Therapy, 5, 401-409.

Kovacs, G. L., Telegdy, G., \& LissaK, K. (1977). Dose-dependent action of corticosteroids on brain serotonin content and passive avoidance behavior. Hormones \& Behavior, 8, 155-165.

LaBar, K. S., Cook, C. A., Torpey, D. C., \& Welsh-Bohmer, K. A.
(2004). Impact of healthy aging on awareness and fear conditioning. Behavioral Neuroscience, 118, 905-915.

LaBar, K. S., Gatenby, J. C., Gore, J. C., LeDoux, J. E., \& Phelps, E. A. (1998). Human amygdala activation during conditioned fear acquisition and extinction: A mixed-trial fMRI study. Neuron, 20,937945

LaBar, K. S., LeDoux, J. E., Spencer, D. D., \& Phelps, E. A. (1995). Impaired fear conditioning following unilateral temporal lobectomy in humans. Journal of Neuroscience, 15, 6846-6855.

LANG, P. J., Bradley, M. M., \& CUthBert, B. N. (2001). International affective picture system (IAPS): Instruction manual and affective ratings (Tech. Rep. No. A-5). Gainesville: University of Florida, Center for Research in Psychophysiology.

LaYton, B., \& Krikorian, R. (2002). Memory mechanisms in posttraumatic stress disorder. Journal of Neuropsychiatry \& Clinical Neurosciences, 14, 254-261.

Luine, V. N., Spencer, R. L., \& McEwen, B. S. (1993). Effects of chronic corticosterone ingestion on spatial memory performance and hippocampal serotonergic function. Brain Research, 616, 65-70.

Luine, V. N., Villegas, M., Martinez, C., \& McEwen, B. S. (1994). Repeated stress causes reversible impairments of spatial memory performance. Brain Research, 639, 167-170.

Lupien, S. J., Gaudreau, S., Tchiteya, B. M., Maheu, F., Sharma, S., NaIr, N. P., Hauger, R. L., McEwen, B. S., \& Meaney, M. J. (1997). Stress-induced declarative memory impairment in healthy elderly subjects: Relationship to cortisol reactivity. Journal of Clinical Endocrinology \& Metabolism, 82, 2070-2075.

Lupien, S. J., Gillin, C., \& HAUger, R. L. (1999). Working memory is more sensitive than declarative memory to the acute effects of corticosteroids: A dose-response study. Behavioral Neuroscience, 13, 1-11.

LuPIEN, S. J., \& McEWEN, B. S. (1997). The acute effects of corticosteroids on cognition: Integration of animal and human model studies. Brain Research Reviews, 24, 1-27.

Lupien, S. J., Wilkinson, C. W., Brière, S., Mènard, C., NG Ying KIN, N. M. K., \& NaIR, N. P. V. (2002). The modulatory effects of corticosteroids on cognition: Studies in young human populations. Psychoneuroendocrinology, 27, 401-416.

Lupien, S. J., Wilkinson, C. W., Brière, S., NG Ying Kin, N. M. K., MeaneY, M. J., \& NaIR, N. P. V. (2002). Acute manipulation of aged human memory by pharmacological manipulation of glucocorticoids. Journal of Clinical Endocrinology \& Metabolism, 87, 3798-3807.

Maheu, F. S., Joober, R., Beaulieu, S., \& Lupien, S. J. (2004). Differential effects of adrenergic and corticosteroid hormonal systems on human short- and long-term declarative memory for emotionally arousing material. Behavioral Neuroscience, 118, 420-428.

McEwEn, B. S., \& SAPOLSKY, R. M. (1995). Stress and cognitive function. Current Opinion in Neurobiology, 5, 205-216.

McGaUGH, J. L. (2004). The amygdala modulates the consolidation of memories of emotionally arousing experiences. Annual Reviews of Neuroscience, 27, 1-28.

McGaugh, J. L., McIntyre, C. K., \& Power, A. E. (2002). Amygdala modulation of memory consolidation: Interaction with other brain systems. Neurobiology of Learning \& Memory, 78, 539-552.

Meaney, M. J., Bhatnagar, S., Larocque, S., McCormick, C., Shanks, N., Sharma, S., Smythe, J., Viau, V., \& Plotsky, P. M. (1993). Individual differences in the hypothalamic-pituitary adrenal stress response and the hypothalamic CRF system. In Y. Taché \& C. Rivier (Eds.), Corticotropin-releasing factor and cytokines: Role in the stress response (Annals of the New York Academy of Sciences, Vol. 697, pp. 70-85). New York: New York Academy of Sciences. Newcomer, J. W., Selke, G., Melson, A. K., Hershey, T., Craft, S., RichaRds, K., \& ALdERSON, A. L. (1999). Decreased memory performance in healthy humans induced by stress-level cortisol treatment. Archives of General Psychiatry, 56, 527-533.

ÖHman, A. (1979). Fear relevance, autonomic conditioning, and phobias: A laboratory model. In P.-O. Sjödén, S. Bates, \& W. S. Dockens III (Eds.), Trends in behavior therapy (pp. 107-134). New York: Academic Press.

OitzL, M. S., \& DE Kloet, E. R. (1992). Selective corticosteroid antagonists modulate specific aspects of spatial orientation learning. Behavioral Neuroscience, 106, 62-71. 
Oitzl, M. S., van Haarst, A. D., \& De Kloet, E. R. (1997). Behavioral and neuroendocrine responses controlled by the concerted action of central mineralocorticoid (MRs) and glucocorticoid receptors (GRs). Psychoneuroendocrinology, 22 (Suppl. 1), S87-S93.

OrR, S. P., Metzger, L. J., \& Pitman, R. K. (2002). Psychophysiology of post-traumatic stress disorder. Psychiatric Clinics of North America, 25, 271-293.

Park, C. R., Campbell, A. M., \& Diamond, D. M. (2001). Chronic psychosocial stress impairs learning and memory and increases sensitivity to yohimbine in adult rats. Biological Psychiatry, 50, 9941004.

Pavlov, I. P. (1927). Conditioned reflexes (G. V. Anrep, Trans.). London: Oxford University Press.

Phelps, E. A., O'Connor, K. F., Cunningham, W. A., Funayama, E. S., Gatenby, J. C., Gore, J. C., \& BanaJi, M. R. (2000). Performance on indirect measures of race evaluation predict amygdala activation. Journal of Cognitive Neuroscience, 12, 729-738.

Piazza, P. V., Maccari, S., Deminiere, J. M., Le Moal, M., Mormede, P., \& Simon, H. (1991). Corticosterone levels determine individual vulnerability to amphetamine self-administration. Proceedings of the National Academy of Sciences, 88, 2088-2092.

Putman, P., van Honk, J., Kessels, R. P. C., Mulder, M., \& KoppeSCHAAR, H. P. F. (2004). Salivary cortisol and short- and long-term memory for emotional faces in healthy young women. Psychoneuroendocrinology, 29, 953-960.

Quirarte, G. L., RoozendaAl, B., \& McGaugh, J. L. (1997). Glucocorticoid enhancement of memory storage involves noradrenergic activation in the basolateral amygdala. Proceedings of the National Academy of Sciences, 94, 14048-14053.

Reul, J. M., \& DE KLoet, E. R. (1985). Two receptor systems for corticosterone in rat brain: Microdistribution and differential occupation. Endocrinology, 117, 2505-2511.

Reul, J. M., Gesing, A., Droste, S., Stec, I. S., Weber, A., Bachmann, C., Bilang-Bleuel, A., Holsboer, F., \& Linthorst, A. C. (2000). The brain mineralocorticoid receptor: Greedy for ligand, mysterious in function. European Journal of Pharmacology, 405, 235-249.

Riad-Fahmy, G., Read, G. F., Walker, R. F., \& Griffiths, K. (1982). Steroids in saliva for assessing endocrine function. Endocrine Reviews, 3, 367-395.

Robinson, T. E., \& Berridge, K. C. (2003). Addiction. Annual Review of Psychology, 54, 25-53.

Rohleder, N., Wolf, J. M., \& Kirschbaum, C. (2003). Glucocorticoid sensitivity in humans: Interindividual differences and acute stress effects. Stress, 6, 207-222.

RoozendaAl, B. (2003). Systems mediating acute glucocorticoid effects on memory consolidation and retrieval. Progress in NeuroPsychopharmacology \& Biological Psychiatry, 27, 1213-1223.

Roozendaal, B., \& McGaugh, J. L. (1996). Amygdaloid nuclei lesions differentially affect glucocorticoid induced memory enhancement in an inhibitory avoidance task. Neurobiology of Learning \& Memory, 65, 1-8.

Rosen, J. B., \& SCHulkin, J. (1998). From normal fear to pathological anxiety. Psychological Review, 105, 325-350.

SANDI, C., \& Rose, S. P. R. (1994). Corticosterone enhances long-term retention in one-day-old chicks trained in a weak passive avoidance learning paradigm. Brain Research, 647, 106-112.

SAPOLSKY, R. M. (1996). Why stress is bad for your brain. Science, 273, $749-750$.

Schumacher, M. (1990). Rapid membrane effects of steroid hormones: An emerging concept in neuroendocrinology. Trends in Neurosciences, 13, 359-362.

Seedat, S., \& Stein, D. J. (2000). Trauma and post-traumatic stress disorder in women: A review. International Clinical Psychopharmacology, 15(Suppl. 3), S25-S33.

Selden, N. R., Robbins, T. W., \& Everitt, B. J. (1990). Enhanced behavioral conditioning to context and impaired behavioral and neuroendocrine responses to conditioned stimuli following ceruleocortical noradrenergic lesions: Support for an attentional hypothesis of central noradrenergic function. Journal of Neuroscience, 10, 531539.
Shirtcliff, E. A., Granger, D. A., Schwartz, E., \& Curran, M. J. (2001). Use of salivary biomarkers in biobehavioral research: Cottonbased sample collection methods can interfere with salivary immunoassay results. Psychoneuroendocrinology, 26, 165-173.

ShORs, T. J. (2001). Acute stress rapidly and persistently enhances memory formation in the male rat. Neurobiology of Learning \& Memory, 75, 10-29.

SHORs, T. J. (2004). Learning during stressful times. Learning \& Memory, 11, 137-144.

Shors, T. J., Weiss, C., \& Thompson, R. F. (1992). Stress-induced facilitation of classical conditioning. Science, 257, 537-539.

Starkman, M. N., Gebarski, S. S., Berent, S., \& Schteingart, D. E. (1992). Hippocampal formation volume, memory dysfunction, and cortisol levels in patients with Cushing's syndrome. Biological Psychiatry, 32, 756-765.

Steptoe, A., Kunz-Ebrecht, S., Owen, N., Feldman, P. J., WillemSen, G., Kirschbaum, C., \& Marmot, M. (2003). Socioeconomic status and stress-related biological responses over the working day. Psychosomatic Medicine, 65, 461-470.

Stone, A. A., Schwartz, J. E., Smyth, J., Kirschbaum, C., Cohen, S., Hellhammer D., \& Grossman, S. (2001). Individual differences in the diurnal cycle of salivary free cortisol: A replication of flattened cycles for some individuals. Psychoneuroendocrinology, 26, 295306.

Strange, B. A., Hurlemann, R., \& Dolan, R. J. (2003). An emotioninduced retrograde amnesia in humans is amygdala- and betaadrenergic-dependent. Proceedings of the National Academy of Sciences, 100, 13626-13631.

Taylor, S. E., Klein, L. C., Lewis, B. P., Gruenewald, T. L., Gurung, R. A. R., \& UpdegrafF, J. A. (2000). Biobehavioral responses to stress in females: Tend-and-befriend, not fight-or-flight. Psychological Review, 107, 411-429.

Veldhuis, H. D., Van Koppen, C., Van Ittersum, M., \& de Kloet, E. R. (1982). Specificity of the adrenal steroid receptor system in rat hippocampus. Endocrinology, 110, 2044-2051.

Wilson, L. M., Wilson, J. R., \& DicARA, L. V. (1975). Facilitation of Pavlovian conditioned cardiodecelerations following preshock in immobilized rats. Physiology \& Behavior, 15, 653-658.

Wolf, O. T. (2003). HPA axis and memory. Best Practice \& Research Clinical Endocrinology \& Metabolism, 17, 287-299.

Wolf, O. T., Convit, A., McHugh, P. F., Kandil, E., Thorn, E. L., De Santi, S., McEwen, B. S., \& de Leon, M. J. (2001). Cortisol differentially affects memory in young and elderly men. Behavioral Neuroscience, 115, 1002-1011.

Wolf, O. T., Schommer, N. C., Hellhammer, D. H., McEwen, B. S., \& Kirschbaum, C. (2001). The relationship between stress induced cortisol levels and memory differs between men and women. Psychoneuroendocrinology, 26, 711-720.

Wolkowitz, O. M., Reus, V. I., Weingartner, H., Thompson, K., Breier, A., Doran, A., Rubinow, D., \& Pickar, D. (1990). Cognitive effects of corticosteroids. American Journal of Psychiatry, 147, 1297-1303.

Wood, G. E., Beylin, A. V., \& Shors, T. J. (2001). The contribution of adrenal and reproductive hormones to the opposing effects of stress on trace conditioning in males versus females. Behavioral Neuroscience, 115, 175-187.

Wood, G. E., \& SHORS, T. J. (1998). Stress facilitates classical conditioning in males, but impairs classical conditioning in females through activational effects of ovarian hormones. Proceedings of the National Academy of Sciences, 95, 4066-4071.

ZorawsKi, M., \& Killcross, S. (2002). Post-training glucocorticoid receptor agonist enhances memory in appetitive and aversive Pavlovian discrete-cue conditioning paradigms. Neurobiology of Learning \& Memory, 78, 458-464.

ZoRAWSKI, M., \& KILLCROSs, S. (2003). Glucocorticoid receptor agonist enhances Pavlovian appetitive conditioning but disrupts outcomespecific associations. Behavioral Neuroscience, 117, 1453-1457.

(Manuscript received September 16, 2004; revision accepted for publication April 18, 2005.) 